Military Technical College

Kobry El-Kobba

Cairo, Egypt

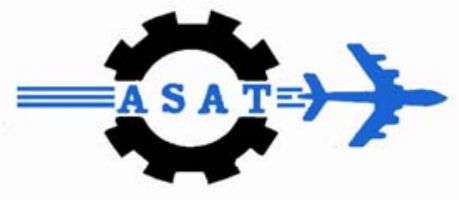

12-th International Conference

on

Aerospace Sciences \&

Aviation Technology

\title{
INTERNAL BALLISTIC SOLUTION OF A TWO-STAGE LIGHT-GAS GUN
}

\author{
Aziz ${ }^{*}$ M. M., Yakout ${ }^{*}$ H. and Riad A. M.
}

\begin{abstract}
Internal ballistic process of two-stage light-gas gun has been solved by many investigators using different approaches. This paper presents two different approaches to predict the interior ballistic parameters of such gun. The first approach is based on isentropic compression of the light gas in the gun pump, whereas the second approach depends on the theory for piston operated compressor in which shock wave was formed and heated the light gas. For each approach, the governing equations have been used to construct a computer program. Predicted time histories of gun parameters associated with gun firing are presented.
\end{abstract}

The predicted results of each approach are compared with available experimental measurements of other investigators; good agreements are generally obtained. For both approaches, samples of the predicted time histories for powder chamber pressure, pump tube pressure, piston velocity and its travel along the gun tube, and projectile velocity and its travel along the barrel are presented for two calibers (12.7 and $28.6 \mathrm{~mm}$ ), together with relevant analyses and discussions.

\section{KEY WORDS}

Gun interior ballistics, gas accelerators, high-speed accelerators, gas dynamics, impact dynamics, two-stage light-gas gun, and experimental ballistics.

\footnotetext{
* Egyptian Armed Forces
} 


\section{INTRODUCTION}

In the early $50 \mathrm{~s}$, the maximum velocity of projectiles fired from conventional guns was about $1.5 \mathrm{~km} / \mathrm{s}$, and those fired from high-muzzle-velocity guns was less than $3 \mathrm{~km} / \mathrm{s}$ [1, 2]. Investigators tried to increase such velocity by using non-conventional methods, such as two-stage-light-gas guns, electro-thermal and electromagnetic launching techniques. Two-Stage Light-Gas (T-S-L-G) guns use gases of low molecular weight, (e.g. hydrogen or helium) as driving gas in the pump tube to propel the projectiles with high velocity up to $8 \mathrm{~km} / \mathrm{s}$ [3].

The gas cycle of T-S-L-G gun has been analyzed by many investigators. The first generation of this gun was developed by Charters et al. [4]. They derived the governing equations of the gas cycle under the assumptions that the process was nearly isentropic. Another scheme of solution of the gas cycle was developed to obtain a constant projectile base pressure during its motion along the barrel. Smith [5] derived the gas cycle equations based on the Lagrangian scheme of unsteady flow in a duct of area change. Wilenius et al. [6] presented analytical solution assuming that the process was quasi-steady gas flow through a duct of area change. Smith and Willenius et al. recommended that it was not possible to obtain constant pressure acting on the projectile base in practice.

Other researchers have tried to improve the performance of the T-S-L-G gun. Curtis [7] modified the gun by: (a) adding a gently tapered section to join the launch and gun pump tube, and (b) constructing a relatively light pump piston of deformable-plastic forward section followed by a heavy rear section. These modifications enabled the gun to operate under an approximately constant base pressure over the first part of the launch run. The CARDE light-gas gun was also modified by extruding the piston through a specific taper nozzle at the end of its travel along the gun tube [8].

Computer codes were also developed to predict the gas cycle of such guns. Piacesi et al. [9] developed their code for calculating the dynamics of such gun using a onedimensional Lagrangian scheme. Their code predicted projectile muzzle velocities higher than the experimental measurements. Glenn [10] developed a code called Arbitrary Lagrangian Eulerian code which gave good predictions of projectile muzzle velocities in comparison with the experimental measurements for LLNL (Lawrence Livermore National Laboratory), and NOL (Naval Ordnance Laboratory) guns.

Recently, the T-S-L-G gun is considered as one of the main accelerators used in impact dynamic studies in many research centers and international universities. For examples; Shock Research Center of Tohoku University studied the impact of cylindrical projectiles with velocities close to $5 \mathrm{~km} / \mathrm{s}$ into a $2 \mathrm{~mm}$-thick aluminum bumper using such gun [11], and University of Manchester Institute of Science and Technology constructed a small caliber of such a gun to study the impact of high-velocity projectiles into thick metallic targets [12].

In this paper, the gun cycle is divided into three main phases namely: ignition, burning and expansion. For each phase, the governing equations representing the gun cycle in powder chamber are similar while the gun process in pump tube are introduced considering the following two cases: (a) isentropic compression of light gas when using heavy piston (model M1), and (b) shock wave formation which propagates and heats 
the light gas when using light piston (model M2, see Ref. [13]). For each model, a computer program was built up to predict the internal ballistic parameters associated with gun firings. Samples of predicted results for two gun calibers (12.7 and $28.6 \mathrm{~mm}$ ) are presented, together with relevant analyses and discussions.

\section{GENERAL DESCRIPTION AND FUNCTION CYCLE OF T-S-L-G GUN}

The T-S-L-G gun consists of two parts; gun tube and barrel. The gun tube consists of two parts separated by a piston, they are pump tube and powder chamber. The pump tube and powder chamber have the same diameter, $D$. The diameter of barrel bore is denoted by $D_{2}$, whereas the barrel length is denoted by $L_{b}$. The length of the gun tube is denoted by $X_{t}$. A diagrammatic scheme of the gun is shown in Fig. 1.

A powder charge is placed at the end of the powder chamber. The chamber is closed at its rear end by a breech. The gun is considered to propel a sub-caliber projectile consisting of sabot and penetrator. The sabot base has a flange to close the pump tube at its front end and the flange is ruptured during the firing process at a predetermined limiting pressure. Before firing, the pump tube is charged with light-gas at a predetermined initial pressure.

The burning of solid propellant inside the powder chamber is a transformation of the chemical energy stored in the propellant grains into heat, kinetic energies, and internal energy of light-gas inside the pump tube. The main assumptions considered due to the burning of propellant grains are listed in Ref. [14].

The gun function cycle is completed when the projectile leaves the muzzle. It is divided into three main phases, namely: (i) ignition, (ii) burning and (iii) expansion. Upon ignition of the propellant, hot gases are generated from the burning surfaces of each propellant grain. All propellant grains are assumed to ignite simultaneously and uniformly. The gas pressure is raised in the powder chamber. The piston starts its movement when the gas pressure behind the piston exceeds the initial charging gas pressure in the pump tube. This pressure represents the initial pressure for the burning phase.

The piston movement due to the gas pressure developed by propellant burning will increase the volume of the powder chamber. When the rate of volume change is equalized by the rate of gas evolving due to burning, the pressure reaches its maximum value. After such point the volume increases and the pressure acting on the piston base decreases. The burning rate of propellant depends on the pressure inside the powder chamber. Due to piston motion, the light-gas in the pump tube is compressed and its pressure is increased. The compression of the light-gas in the pump tube has been treated using two different approaches; these are: (i) isentropic compression, and (ii) shock wave propagation which increases the pressure of the light-gas. The burning phase is continued until a complete burning of propellant mass occurred.

The expanding hot gases will force the piston against the light-gas in the pump tube. So, the pressure inside the pump tube will increase and consequently resist the piston motion. The light-gas compression approaches (models M1 and M2) are applied during this phase. When the gas pressure inside the pump tube reaches a certain value 
corresponding to the limit pressure $\mathrm{P}_{\mathrm{L}}$, the flange of sabot is completely teared. Then, the light-gas accelerates the projectile along the barrel. The value of limit pressure is determined experimentally based on the required range of projectile muzzle velocity.

When the projectile starts its motion, its velocity is less than the piston velocity. So, the pressure in the pump tube exceeds the limit pressure $P_{L}$. The projectile accelerates along the barrel while, the piston decelerates until it stops. Depending on the gun dimensions and its other operating parameters, the piston may start to move backwards against powder chamber pressure. If the piston moves backwards against powder chamber pressure, the pressure behind the projectile decreases due to a large change in the gas volume behind while, the powder chamber pressure starts to increase again.

When the projectile leaves the muzzle, the pressure inside the barrel returns to atmospheric. The pressure in the powder chamber is slightly greater than the pump tube gas pressure, and the piston then moves slowly to the tube end of the gun with small dimensions.

The fundamental equations of the gun function cycle consist of: (i) equation of state of the gas due to propellant burning behind the piston, (ii) burning equation, and (iii) equations of piston and projectile motions. These fundamental equations together with the proper assumptions and mathematical manipulations for both models (M1 and M2) are available in Refs. [13-15].

For each model, the main equations are compiled into a computer program, the input data for each model are determined. Each model is capable of predicting the following: (i) pressure-time histories in pump tube and powder chamber, respectively, (ii) timehistories of piston velocity and its displacement along the gun tube, projectile velocity and its displacement along the gun barrel, respectively, (iii) total time of gun function cycle, (iv) total time of projectile travel along the barrel, and (v) projectile muzzle velocity.

\section{RESULTS AND DISCUSSIONS}

In the following, the obtained results are classified into: (i) validation of each model predictions with the available experimental measurements of other investigators, and (ii) samples of predicted time histories of main parameters associated with gun function cycle using both models for two different calibers.

\section{(i) Validation of Predicted Results}

Table 1 lists the input data of 12.7 and $28.6 \mathrm{~mm}$ T-S-L-G guns to the computer program of each model, respectively. These data are classified into four main group, these are: (i) gun dimensions, (ii) propellant data, (iii) gun operating conditions, and (iv) other relevant data. 
Table 1. Input data to the computer program of each model for gun calibers of 12.7 and $28.6 \mathrm{~mm}$, respectively.

\begin{tabular}{|c|c|c|c|}
\hline \multirow{2}{*}{$\begin{array}{c}\text { Group } \\
\text { No. }\end{array}$} & \multirow{2}{*}{ Input data } & \multicolumn{2}{|c|}{ Gun caliber, $\mathrm{D}_{2}[\mathrm{~mm}]$} \\
\hline & & 12.7 & 28.6 \\
\hline 1 & $\begin{array}{l}\text { (i) Gun dimensions: } \\
\text { - Length of conical section of gun tube, } X_{1}[\mathrm{~m}] \\
\text { - Barrel bore diameter, } D_{2}[\mathrm{~m}] \\
\text { - Barrel length, } L_{b}[\mathrm{~m}] \\
\text { - Internal diameter of gun tube, } D[\mathrm{~m}] \\
\text { - Gun tube length, } \mathrm{X}_{t}[\mathrm{~m}]\end{array}$ & $\begin{array}{c}0.15 \\
0.0127 \\
1.9 \\
0.03 \\
1.3 \\
\end{array}$ & $\begin{array}{c}0.0 \\
0.0286 \\
8.28 \\
0.09 \\
9.02 \\
\end{array}$ \\
\hline 2 & $\begin{array}{l}\text { (ii) Propellant data: } \\
\text { - Propellant force constant, } \lambda[\mathrm{N} \cdot \mathrm{m} / \mathrm{kg}] \\
\text { - Propellant density, } \delta\left[\mathrm{kg} / \mathrm{m}^{3}\right] \\
\text { - Co-volume, } \eta\left[\mathrm{m}^{3} / \mathrm{kg}\right] \\
\text { - Burning rate constant, } \mathrm{u}_{1}\left[(\mathrm{~m} / \mathrm{s}) /\left(\mathrm{N} / \mathrm{m}^{2}\right)\right] \\
\text { - Half web size of propellant grain, } \mathrm{e}_{1}[\mathrm{~m}] \\
\text { - Burning rate exponent, } \alpha \\
\text { - Specific heat ratio of product gaseous, } \gamma\end{array}$ & $\begin{array}{l}1.159 \mathrm{E}+6 \\
1.6 \mathrm{E}+3 \\
0.8 \mathrm{E}-3 \\
3.102 \mathrm{E}-8 \\
1.27 \mathrm{E}-4 \\
0.845 \\
1.2238 \\
\end{array}$ & $\begin{array}{l}0.935 \mathrm{E}+6 \\
1.58 \mathrm{E}+3 \\
1.081 \mathrm{E}-3 \\
1.101 \mathrm{E}-7 \\
0.538 \mathrm{E}-4 \\
0.702 \\
1.2543 \\
\end{array}$ \\
\hline 3 & $\begin{array}{l}\text { (iii) Gun operating conditions: } \\
\text { - Shear strength of the diaphragm, } P_{L}[M P a] \\
\text { - Initial pressure in pump tube, } P_{0}^{\prime}[\mathrm{MPa}]\end{array}$ & $\begin{array}{l}35.0 \\
10.0 \\
\end{array}$ & $\begin{array}{c}68.0 \\
0.76-1.17\end{array}$ \\
\hline 4 & $\begin{array}{l}\text { (iv) Other relevant data: } \\
\text { - Charge mass, C }[\mathrm{kg}] \\
\text { - Piston mass, m }[\mathrm{kg}] \\
\text { - Specific heat ratio of helium, } \gamma^{\prime} \\
\text { - Gas constant of helium, }\left[\mathrm{J} / \mathrm{kg} .{ }^{\circ} \mathrm{K}\right] \\
\text { - Specific heat ratio of hydrogen, } \gamma^{\prime} \\
\text { - Gas constant of hydrogen, }\left[\mathrm{J} / \mathrm{kg} .{ }^{\circ} \mathrm{K}\right] \\
\text { - Projectile mass, } \mathrm{M}_{\mathrm{pr}}[\mathrm{kg}]\end{array}$ & $\begin{array}{c}0.007-0.011 \\
0.11-0.115 \\
1.66 \\
2077 \\
-- \\
-- \\
17\end{array}$ & $\begin{array}{c}2.98 \\
6.54-11.01 \\
1.66 \\
2077 \\
1.4 \\
4124 \\
26-40.1\end{array}$ \\
\hline
\end{tabular}

\section{$12.7 \mathrm{~mm}$ two-stage light-gas gun}

Table 2 lists the predicted results using both models $M 1$ and $M 2$, together with experimental measurements obtained by Riad and Leech [12] for charge masses ranging from 7-11 g. For each charge mass, the results include: (I) powder chamber peak pressure, (ii) peak pressure inside pump tube, and (iii) projectile muzzle velocity, when firing from $12.7 \mathrm{~mm}$ T-S-LG gun.

Good agreement was generally obtained between the predictions of models M1 and M2 and the corresponding experimental measurements of Ref. [12]. For the powder chamber, the absolute of maximum differences between the predicted peak pressures using both models and the corresponding experimental measurements were found to be $8.3 \%$, at a charge mass of $7 \mathrm{~g}$. For the pump tube, the absolute of maximum difference between the predicted peak pressure using model M1 and the corresponding measurement was found to be $12 \%$ at the same charge mass. The predicted peak pressures in pump tube using model $\mathrm{M} 2$ and the corresponding measurements were in bad agreement. This may be attributed to the use of shock wave principle in simulating 
Table 2. Predicted results of $12.7 \mathrm{~mm}$ T-S-L-G gun of models $M 1, M 2$, and experimental results of Ref. [12].

\begin{tabular}{|c|c|c|c|c|c|c|c|c|c|c|c|c|c|c|c|}
\hline \multirow{2}{*}{ 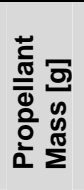 } & \multicolumn{3}{|c|}{$\begin{array}{c}\text { Max. powder } \\
\text { chamber pressure } \\
{[\mathrm{MPa}]}\end{array}$} & \multicolumn{2}{|c|}{$\begin{array}{l}\text { Difference } \\
{[\%]}\end{array}$} & \multicolumn{3}{|c|}{$\begin{array}{l}\text { Max. pump tube } \\
\text { pressure [MPa] }\end{array}$} & \multicolumn{2}{|c|}{$\begin{array}{l}\text { Difference } \\
{[\%]}\end{array}$} & \multicolumn{3}{|c|}{$\begin{array}{l}\text { Projectile muzzle } \\
\text { velocity }[\mathrm{m} / \mathrm{s}]\end{array}$} & \multicolumn{2}{|c|}{$\begin{array}{c}\text { Difference } \\
{[\%]}\end{array}$} \\
\hline & M1 & M2 & $\begin{array}{l}\text { Exp. } \\
{[12]}\end{array}$ & M1 & M2 & M1 & M2 & $\begin{array}{l}\text { Exp. } \\
{[12]}\end{array}$ & M1 & M2 & M1 & M2 & $\begin{array}{l}\text { Exp. } \\
{[12]}\end{array}$ & M1 & M2 \\
\hline 7 & 110 & 110 & 120 & 8.3 & 8.3 & 75.4 & 59.8 & 86 & 12 & 30 & 818 & 874.3 & 758 & 8 & 15 \\
\hline 8 & 134 & 135 & 143 & 6.3 & 5.6 & 95.4 & 72.6 & 100 & 4.6 & 27 & 901.3 & 936.9 & 874 & 3 & 7.2 \\
\hline 9 & 161 & 162 & 165 & 2.4 & 1.8 & 120 & 87.1 & 125 & 4 & 30 & 981 & 1002 & 981 & 0 & 2.1 \\
\hline 10 & 192 & 193 & 193 & 0.5 & 0 & 149 & 80.9 & 151 & 1.3 & 46 & 1059 & 1070 & 1078 & 1.8 & 0.7 \\
\hline 11 & 228 & 229 & 220 & 4 & 4 & 181 & 91.5 & 180 & 0.5 & 49 & 1132 & 1128 & 1168 & 3.1 & 3.4 \\
\hline
\end{tabular}

the internal ballistic process of gun having small dimensions, and relatively heavy piston mass. In addition, the absolute of maximum differences between the measured projectile muzzle velocities and the corresponding predicted velocities using both models were found to be $8 \%$ and $15 \%$, respectively, at a charge mass of $7 \mathrm{~g}$.

Figure 2 plots the measured time history of the powder chamber pressure using a charge mass of $8 \mathrm{~g}$ until the moment at which the projectile leaves the muzzle [12]. For the same charge mass, the predicted time histories of the powder chamber pressure using both models are depicted on the same figure, and good agreement was obtained. Moreover, it is clear that the powder chamber pressure peaks, then the pressure rapidly decreases to its minimum value and increases again at the end of gun function cycle due to the backwards motion of the piston.

Figure 3 shows the measured time history of the pump tube pressure using a charge mass of $8 \mathrm{~g}$ [12]. For the same charge mass, the predicted time history of pump tube pressure using both models are also depicted on the same figure. Good agreement was generally obtained between the measured time history and the corresponding prediction of model M1. However, a difference was found between the measured time history and the corresponding prediction of model M2. This could be attributed to the mathematical treatment which considers shock wave propagation and reflection from the end of the tube and piston face. The reflected shock wave from the end of pump tube or piston face raises the pressure behind it at very short time. The predicted time history of pump tube pressure could include more than one peak depending on the number of shock wave reflections from the end of pump tube and piston face.

For model M1, the predicted time history of pump tube pressure shows a low rate of increase in light-gas pressure at the beginning of gun function cycle. Then, the pressure of light-gas in pump tube increases due to its compression by piston motion. At the limit pressure, the diaphragm shears, then the projectile starts its motion along the barrel. Because the piston moves faster than the projectile when the pressure inside pump tube exceeds the limit pressure, the pump tube pressure increases until it reaches its maximum value. Then, the pump tube pressure decreases due to the increase in light-gas volume. 


\section{$28.6 \mathrm{~mm}$ two-stage light-gas gun}

Table 3 lists the predicted results using both models $M 1$ and $M 2$, together with experimental measurements obtained by Munson and May [16] when using $28.6 \mathrm{~mm}$ T-S-L-G gun for a series of tests with different data. The charge mass was $2.98 \mathrm{~kg}$, the piston masses ranged from 6.5 to $11 \mathrm{~kg}$, the projectile masses ranged from 26 to $40 \mathrm{~g}$, and different operating light-gas (e.g. helium, hydrogen). For each experiment, peak pressure inside powder chamber and projectile muzzle velocity are available. The data of each experiment are fed into the computer program of each model. Good agreement was generally obtained between the models predictions and the corresponding experimental measurements of Ref. [16]. For the powder chamber, the absolute of maximum differences between the measured internal peak pressures and the corresponding predictions using models $M 1$ and $M 2$ were found to be $11.5 \%$ and $10 \%$, respectively. The absolute of maximum differences between the measured projectile muzzle velocities and the corresponding predictions of both models were found to be $10.6 \%$ and $9.7 \%$, respectively.

\section{(ii) Samples of Predicted Time-Histories Results}

\section{$12.7 \mathrm{~mm}$ two-stage light-gas gun}

Figure 4 depicts the predicted piston velocity-time histories using both models for a charge mass of $8 \mathrm{~g}$. For each model, the present figure shows that the piston velocity peaks, then decreases, stops and starts to move backwards during the gun function cycle time. The predicted times by both models at which the piston velocity reaches its maximum value are different. This may be attributed to the predicted built-up pump tube pressure and its relation with powder chamber pressure. Because the predicted pump tube pressure by model M2 is lower than that of model M1, the predicted piston velocity by model M2 peaks earlier than that predicted by model M1. Also, the predicted piston momentum by model M2 is lower than that predicted by model M1. Therefore, the predicted piston travel along the gun tube by the model M2 is smaller than that predicted by model M1. This leads to the early predicted stop of piston motion by model M2 and it starts to move backwards against the gases pressure due to propellant burning in the powder chamber. Moreover, the predicted backward motion of the piston by model M2 takes a smaller time than that predicted by model M1. This is due to the low predicted pump tube pressure when the piston stops in comparison with that predicted by model M1.

The predicted maximum piston velocity along the gun tube and the time at which the piston velocity peaks using model M1 are $460 \mathrm{~m} / \mathrm{s}$ and $1.41 \mathrm{~ms}$, respectively, whereas the corresponding predictions using model M2 are $425 \mathrm{~m} / \mathrm{s}$ and $1.06 \mathrm{~ms}$, respectively. Both models also predict that the times at which the piston stops along the gun tube are 3.04 and $2.65 \mathrm{~ms}$, respectively.

Figure 5 plots the piston displacement-time history predicted by each model using the same charge mass. Both predicted histories show same trends Moreover, the predicted piston displacement along the gun tube by model M2 is smaller than that predicted by model M1. The predicted piston displacement along the gun tube until it stops using 
Table 3. Predicted results of $28.6 \mathrm{~mm}$ T-S-L-G gun using models M1and M2, and experimental results of Ref. [16].

\begin{tabular}{|c|c|c|c|c|c|c|c|c|c|c|c|c|c|c|c|c|c|c|}
\hline \multirow[t]{2}{*}{$\begin{array}{l}\text { Ser. } \\
\text { No. }\end{array}$} & \multirow{2}{*}{ 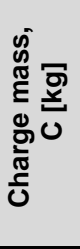 } & \multirow[t]{2}{*}{ 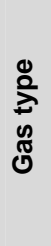 } & \multirow{2}{*}{ 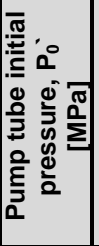 } & \multirow{2}{*}{ 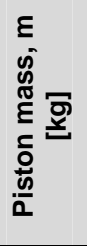 } & \multirow{2}{*}{ 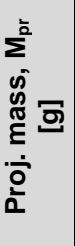 } & \multicolumn{3}{|c|}{$\begin{array}{c}\text { Peak powder } \\
\text { chamber pressure } \\
\text { [MPa] }\end{array}$} & \multicolumn{2}{|c|}{ 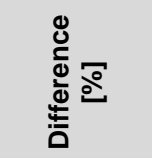 } & \multicolumn{3}{|c|}{$\begin{array}{c}\text { Peak pump tube } \\
\text { pressure } \\
\text { [MPa] }\end{array}$} & \multicolumn{3}{|c|}{$\begin{array}{l}\text { Projectile muzzle } \\
\text { velocity, } \\
\text { V2 }[\mathrm{m} / \mathrm{s}]\end{array}$} & \multicolumn{2}{|c|}{ 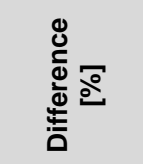 } \\
\hline & & & & & & M1 & M2 & $\begin{array}{l}\text { Exp. } \\
\text { [16] }\end{array}$ & M1 & M2 & M1 & M2 & $\begin{array}{l}\text { Exp. } \\
\text { [16] }\end{array}$ & M1 & M2 & $\begin{array}{l}\text { Exp. } \\
\text { [16] }\end{array}$ & M1 & M2 \\
\hline 1 & 2.98 & $\mathrm{H} 2$ & 0.76 & 6.54 & 26.4 & 26 & 25.5 & 25.5 & 1.96 & 0 & 140 & 133 & * & 5413 & 5515 & 5210 & 3.9 & 5.9 \\
\hline 2 & 2.98 & $\mathrm{H} 2$ & 0.76 & 6.84 & 40.1 & 26.6 & 26.2 & 25.2 & 5.5 & 4 & 167 & 158 & * & 4883 & 5004 & 4860 & 0.5 & 3 \\
\hline 3 & 2.98 & $\mathrm{H} 2$ & 0.76 & 6.81 & 26.1 & 26.5 & 26.1 & 26.2 & 1.14 & 0.4 & 142 & 134 & * & 5467 & 5571 & 5270 & 3.7 & 5.7 \\
\hline 4 & 2.98 & $\mathrm{H} 2$ & 0.76 & 11.01 & 26 & 35 & 34.6 & 31.4 & 11.5 & 10 & 127 & 134 & * & 5267 & 5628 & 5420 & 2.8 & 3.8 \\
\hline 5 & 2.98 & $\mathrm{He}$ & 0.76 & 6.79 & 26 & 26.6 & 26.2 & 25.5 & 4.3 & 2.7 & 124 & 113 & ז & 4574 & 4776 & 4410 & 3.7 & 8.3 \\
\hline 6 & 2.98 & $\mathrm{H} 2$ & 1.17 & 6.8 & 26.1 & 27.1 & 26.7 & 26.5 & 2.3 & 0.8 & 123 & 111 & & 5190 & 5143 & 4690 & 10.6 & 9.7 \\
\hline
\end{tabular}

* No measurements.

model M1 is about $0.92 \mathrm{~m}$, whereas the corresponding predicted piston displacement using model M2 is $0.64 \mathrm{~m}$.

Figure 6 presents the predicted projectile velocity-time histories using both models for a charge mass of $8 \mathrm{~g}$. It is clear that the predicted time history by model M1 is slightly different than that predicted by the model M2. This may be attributed to the calculated work done of the light-gas that acts on projectile base and drives it during its motion along the barrel; it is higher in model M2 compared with model M1. Therefore, the predicted muzzle velocity by model $\mathrm{M} 2$ is greater than that predicted by model $\mathrm{M} 1$. The predicted muzzle velocities by models M1 and M2 are 901 and 937, respectively.

Figure 7 depicts the predicted projectile displacement-time histories using both models for the same charge mass. It can be seen from the figure that the predicted projectile displacement along the gun barrel by model M1 is slightly greater than that predicted by model M2. In addition, the predicted projectile traveling times along the gun barrel using models $\mathrm{M} 1$ and $\mathrm{M} 2$ are 3.33 and $3.38 \mathrm{~ms}$, respectively.

\section{$28.6 \mathrm{~mm}$ two-stage light-gas gun}

In the following, the computer program of each model is fed by the data of experiment no. 5 listed in Table 3. The other input data to each model are listed in Table 1. Figure 8 plots the powder chamber pressure-time histories predicted by the two models until the moment at which the projectile leaves the muzzle. The present figure shows that the initial pressure $P_{0}$ at which the piston starts its motion is $6.35 \mathrm{MPa}$ while the initial pressure in pump tube $\mathrm{P}_{\mathrm{o}}$ ' is $0.76 \mathrm{MPa}$. This is due to the use of breaking valve in the powder chamber of such gun which ruptures at this initial pressure then, the propellant gases act directly on the piston base. This figure also shows that the predicted powder chamber pressure increases gradually until it reaches its peak, then the pressure decreases due to increasing the rate of change of volume behind the piston. 
Figure 9 depicts the pump tube pressure-time histories predicted by both models using the same input data until the projectile leaves the muzzle. For each model, the present figure shows that the predicted pump tube internal pressure increases slightly at the beginning of gun cycle. Then, the pressure increases rapidly until it reaches its peak. The pressure then decreases because the volume between projectile base and piston face for model M1 or between projectile base and reflected shock wave for model M2 increases due to the high projectile velocity along the barrel compared with the piston speed along the gun tube. In addition, the predicted history of pump tube pressure by model M2 has the same trend as that predicted by model M1; this is due to the low gas pressure behind weak shock wave created in gun with great dimensions. Also, multiple shock wave reflections are associated with its propagation in such case.

Figure 10 illustrates the predicted piston velocity-time histories using both models. For each model, the figure shows that the time histories of piston velocity predicted by both models have similar trends where the piston velocity peaks then decreases during the gun function cycle. Moreover, both models predict that the piston moves only forward during the gun function cycle. Figure 11 plots the predicted piston position-time history by each model using the same input data. It is clear from the figure that the time histories predicted by both models are almost identical.

The predicted maximum piston velocity and the time at which the piston velocity peaks using model M1 are $412.8 \mathrm{~m} / \mathrm{s}$ and $30.9 \mathrm{~ms}$, whereas the corresponding predictions using model M2 are $418.7 \mathrm{~m} / \mathrm{s}$ and $30.4 \mathrm{~ms}$, respectively. Also, the predicted maximum piston displacement along the gun tube by model $\mathrm{M} 1$ is $7.4 \mathrm{~m}$ whereas the corresponding prediction using model M2 is $7.53 \mathrm{~m}$.

Figure 12 depicts the predicted projectile velocity-time histories using both models for the same input data. It can be seen that the predicted time histories by both models have similar trends. Moreover, the figure shows that the predicted projectile velocity along the gun barrel by model M2 is greater than that predicted by model M1. This may be attributed to the relatively predicted high pressure in the pump tube using model M2 compared with that predicted by model M1. Figure 13 depicts the corresponding predicted projectile displacement-time histories. The predicted projectile muzzle velocity and the corresponding traveling time along the barrel by model M1 are $4574 \mathrm{~m} / \mathrm{s}$ and $3.46 \mathrm{~ms}$, whereas the corresponding predictions using model M2 are $4776 \mathrm{~m} / \mathrm{s}$ and $3.3 \mathrm{~ms}$, respectively.

\section{CONCLUSIONS}

Based on the present work, the following conclusions have been drawn:

- For each model (M1 and M2), good agreement is generally obtained between the available experimental measurements of other investigators and the corresponding predictions except the peak pressures in the pump tube for the $12.7 \mathrm{~mm}$ gun.

- Similar trends between the predictions of each internal ballistic parameter using both models for each gun caliber are generally obtained, except the time histories of the pump tube internal pressures for the $12.7 \mathrm{~mm}$ gun. 
- For the $12.7 \mathrm{~mm}$ gun, the bad agreement between the predictions of both models for the pump tube pressure may be connected with the formation of a strong shock wave which propagates and raises the pressure of the light-gas than that when considering the compression process to be isentropic during the gun function cycle.

- Further analytical study for small gun calibers is needed to predict similar trends for the pump tube pressure-time histories using both models.

\section{REFERENCES}

[1] Seigel, A. E., "Theory of High-Muzzle-Velocity Guns", Interior Ballistics of Guns, Prog. In Astro. \& Aero. Vol. 66, edited by Krier, H. and Summerfield, M., AIAA, New York, pp. 135-175, (1979).

[2] Bogdanoff, D. W. and Miller, R. J., "Improving the Performance of Two-Stage Gas Guns by Adding a Diaphragm in the Pump Tube", Int. J. Impact Eng., Vol. 17, pp. 81-92, (1995).

[3] Charters, A.C., "The Early Years of Aerodynamics Ranges, Light-Gas Guns, and High-Velocity Impact", Int. J. Impact Engineering, Vol. 17, pp. 151-182, (1995).

[4] Charters, A. C., Dernardo, B. P. and Rossow, V. L., "Development of a PistonCompression Type Light-Gas Gun for Launching of Free Flight Models at HighVelocity", NACA Report, No. TN 4143, (1957).

[5] Smith F., "Theory of a Two-Stage Hypervelocity Launcher to Give Constant Driving Pressure at the Model", J. Fluid Mech., Vol. 17, pp. 113-125, (1963).

[6] Wilenius G. P., Cloutier, M. and Cowan, P. L., "A Theoretical Analysis of a Constant Base Pressure Light-Gas Gun”, CARDE TM 703/62, (1962).

[7] Curtis, J. S., "An Accelerated Reservoir Light-Gas Gun", NASA Report, No. TN D-1144, (1962).

[8] Leech, C. M., "Piston Extrusion in Light-Gas Guns", CARDE TR 580/67, (1967).

[9] Piacesi, R., Gates, D. F. and Siegel, A. E., "Computer Analysis of Two-Stage Hypervelocity Model Launchers", NOL TR 62-87, (1963).

[10] Glenn, L. A., "Performance Analysis of the Two-Stage Light-Gas Gun", Lawrence Livermore national Laboratory Report UCRL-96021, (1987).

[11] Ramjaun D., Shinohara, M., Kato, I. and Takayama, K., "Spectroscopic Study of Radiation Associated with Hypervelocity Impact", Shock Wave Research Center, Tohoku University, Aoba, Sendia, Japan, (2001).

[12] Riad, A. M. and Leech, C. M., "An Experimental Investigation of Normal Perforation of High-Speed Projectiles in Metallic Plates", Proc. of the $3^{\text {rd }}$ Int. Conf. on AMME, M.T.C., Cairo, (1996).

[13] Winter, D. F., "Multiple Shock Compression Using a Piston of Finite Weight", J. Fluid Mech., Vol. 8, pp. 264-272, (1962).

[14] Riad, A. M. and Leech, C. M., "Internal Ballistic Solution and Design of Small Caliber Two-Stage Light-Gas Gun", proc. of the $2^{\text {nd }}$ Int. Conf. on AMME, M.T.C., pp. 161-181, Cairo, (1994).

[15] Aziz, M. M., Internal Ballistic Solution of Two-Stage Light-Gas Gun, M. Sc. Thesis, M. T. C, Cairo, to be defended.

[16] D. E. Munson and R. P. May, "Interior Ballistics of a Two-Stage Light Gas Gun Using Velocity Interferometry”, AIAA Journal, Vol. 14, No.2, pp. 235-242, (1976). 


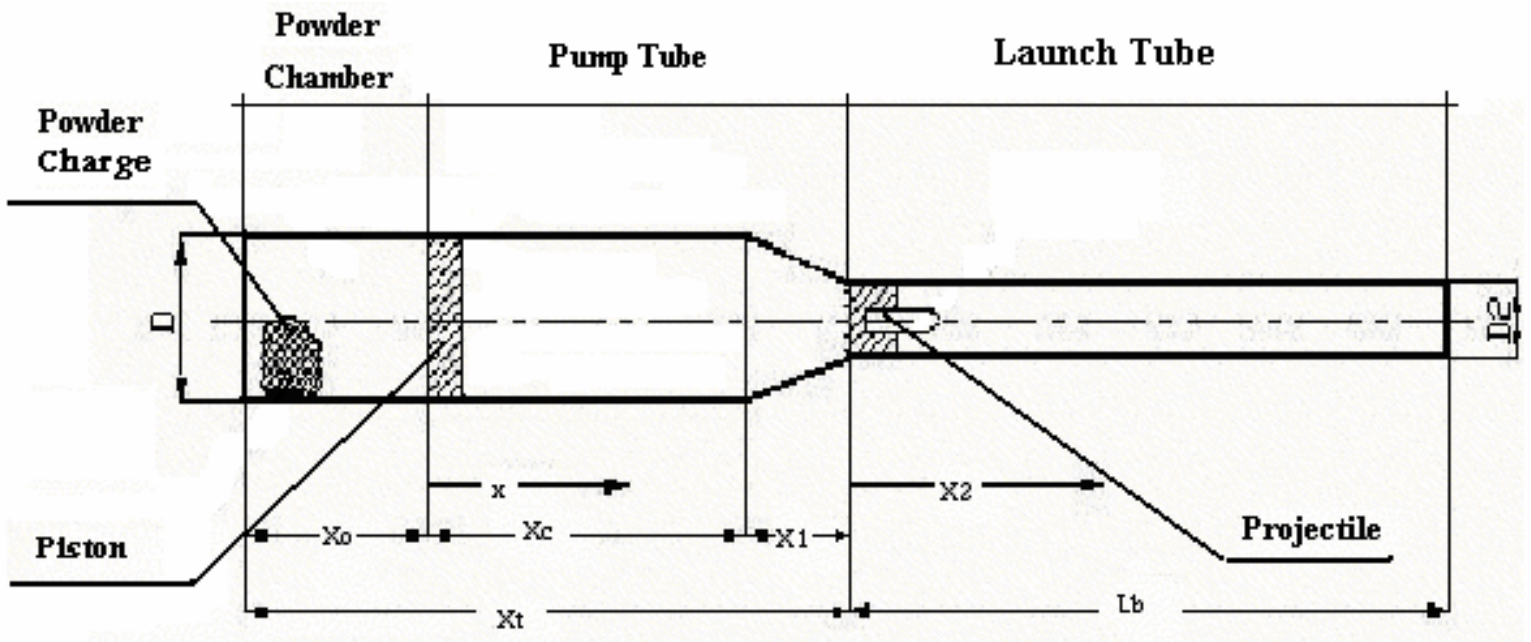

Fig. 1. Diagrammatic scheme of the two-stage light-gas gun.

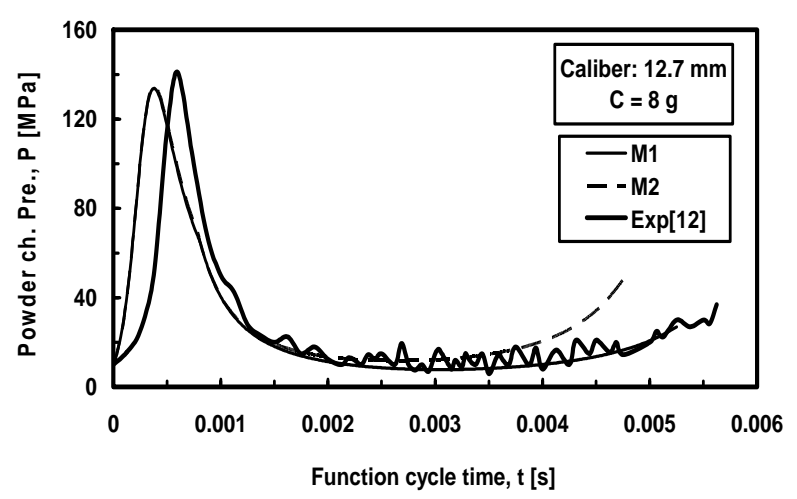

Fig. 2. Predicted pressure-time histories of powder chamber using models $\mathrm{M} 1$ and $\mathrm{M} 2$, respectively, and measurements of Ref. [12].

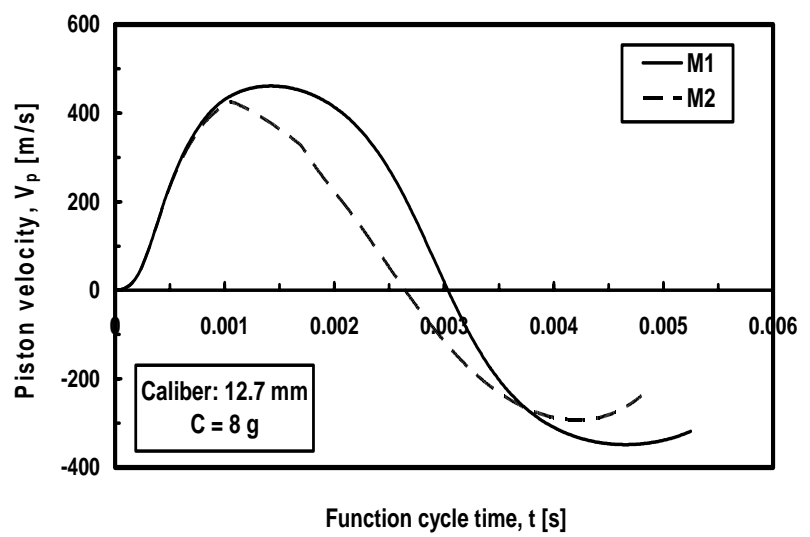

Fig. 4. Predicted piston velocity-time histories using models M1 and M2.

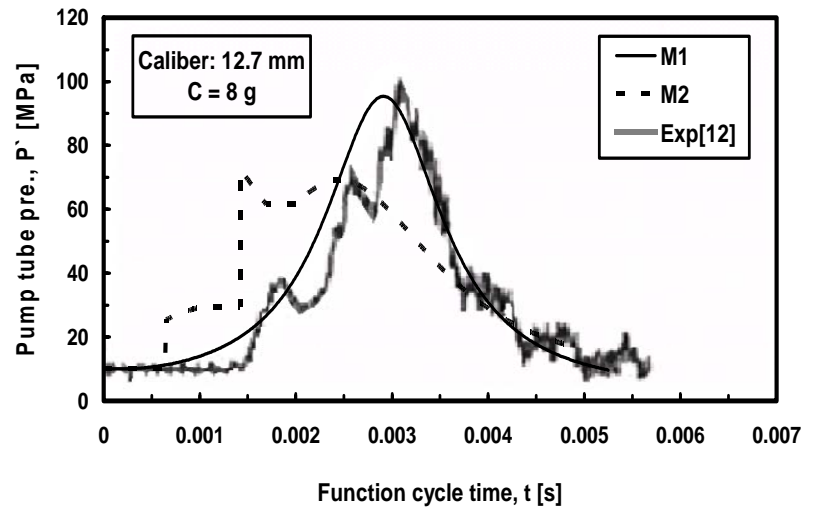

Fig. 3. Predicted pressure-time histories of pump tube using models M1 and M2, respectively, and measurements of Ref. [12].

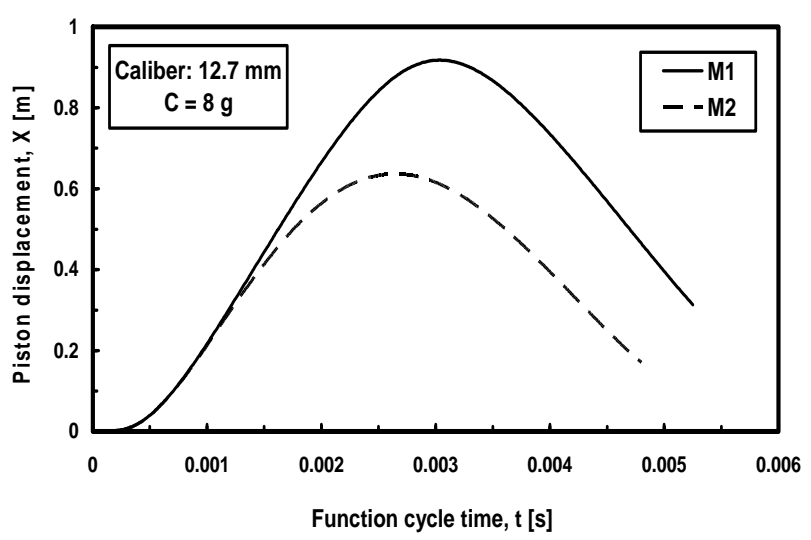

Fig. 5. Predicted piston displacement-time histories using models M1 and M2. 


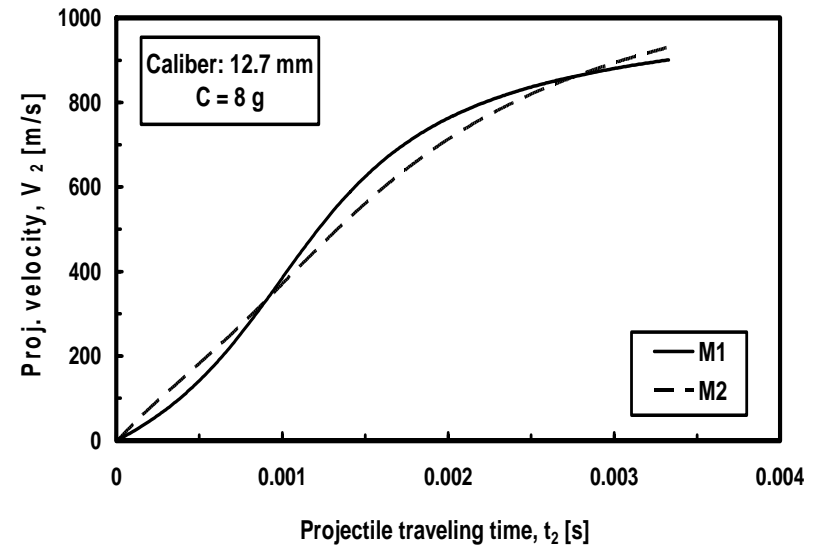

Fig. 6. Predicted projectile velocity vs. Time using models M1 and M2.

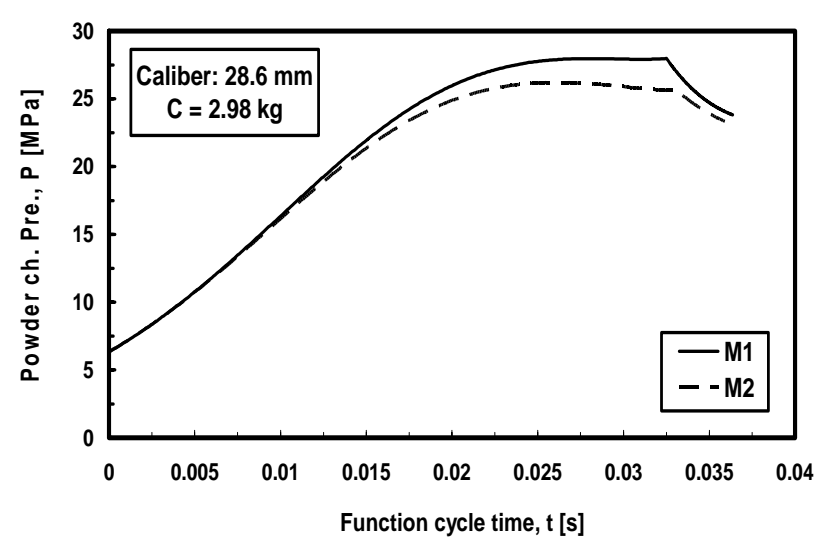

Fig. 8. Predicted powder chamber pressure-time histories using models M1 and M2.

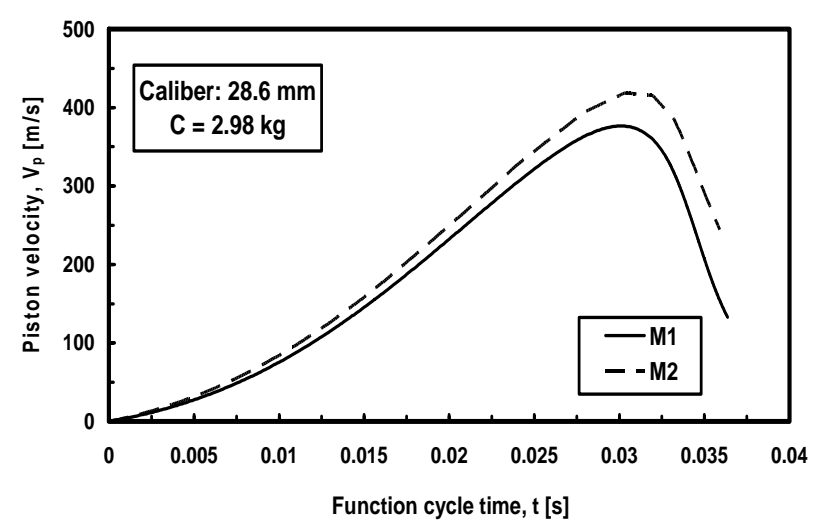

Fig. 10. Predicted piston velocity-time histories using models M1 and M2.

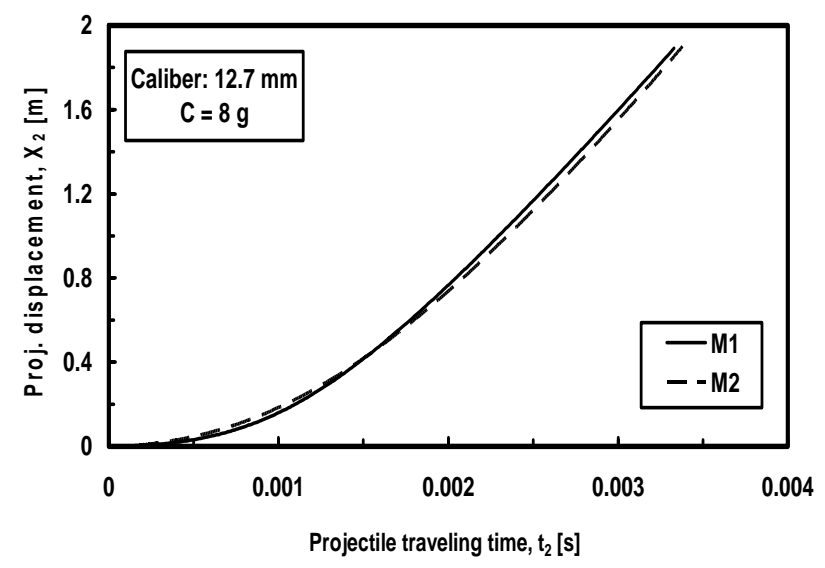

Fig. 7. Predicted projectile position-time histories using models M1 and M2.

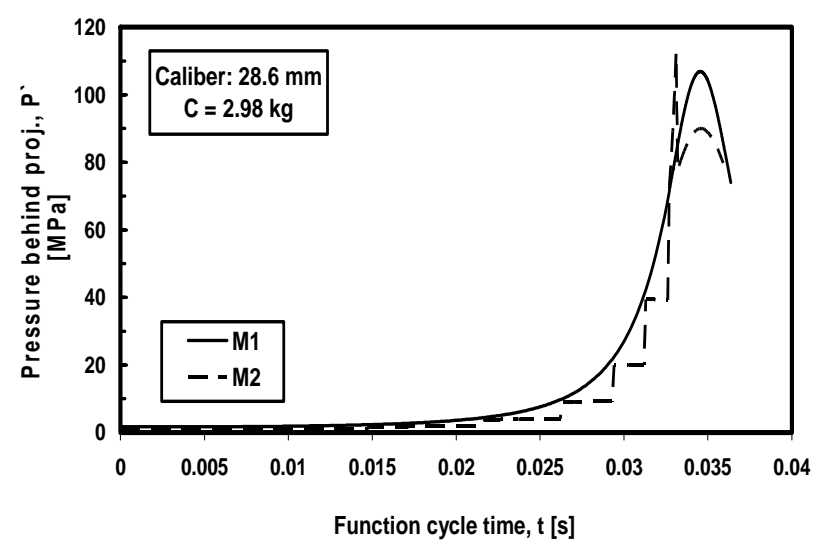

Fig. 9. Predicted pump tube pressure vs. time using models M1 and M2.

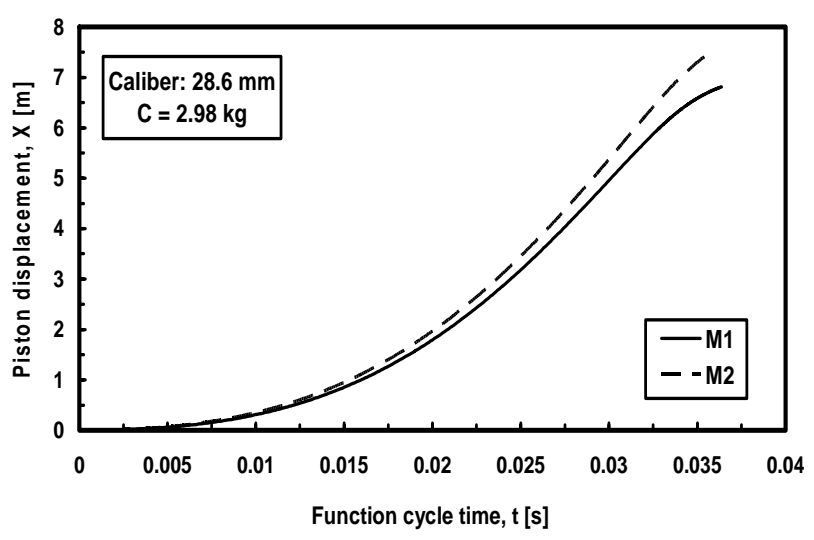

Fig. 11. Predicted piston displacement-time histories using models M1 and M2. 


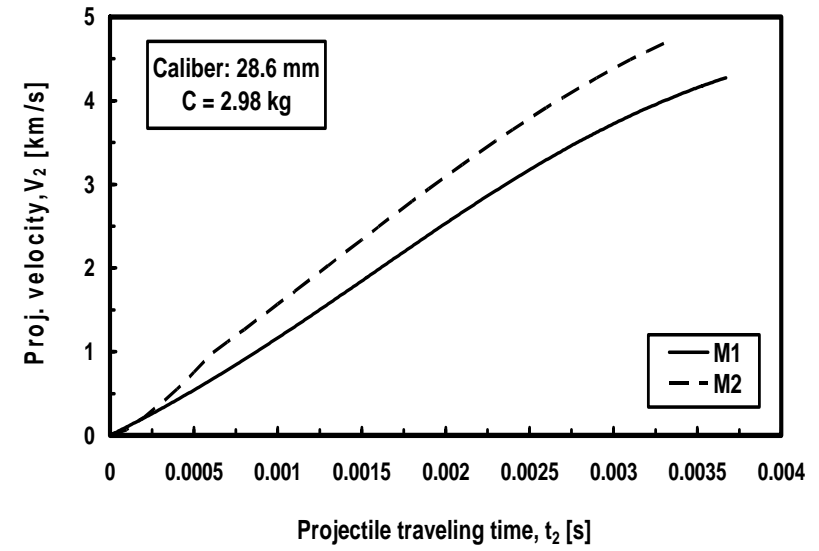

Fig. 12. Predicted projectile velocity-time histories using models M1 and M2.

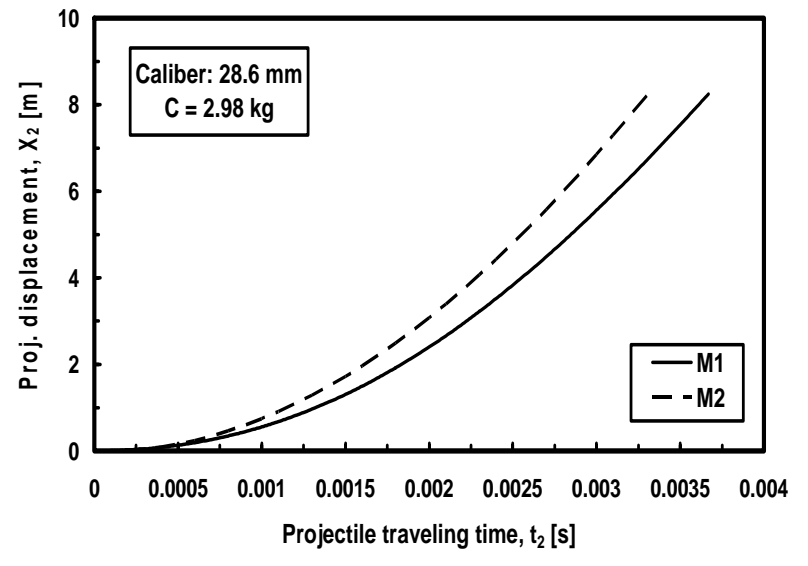

Fig. 13. Predicted projectile displacement-time histories using models M1 and M2. 